\title{
Hybrid Strategy, Ambidexterity and Environment: toward an Integrated Typology
}

\author{
Alexandre Lapersonne*, Nitin Sanghavi, Claudio De Mattos
}

Manchester Business School, The University of Manchester, UK

Copyright $(2015$ by authors, all rights reserved. Authors agree that this article remains permanently open access under the terms of the Creative Commons Attribution License 4.0 International License

\begin{abstract}
Hybrid strategy, which emerged as a contingency option to Porter's generic strategies framework [1], defends that in a dynamic environment the simultaneous pursuit of "Low Cost" and "Differentiation" approaches is fundamental for the short-term performance and long-term survival of the firm. A vast amount of literature supports the benefits of adopting a mixed approach of strategy: several empirical studies have proved that a hybrid strategy establishes a firm's performance superiority over the pure strategy choice. The hybrid literature has concentrated on the performance linkage and on the debate countering the pure strategy approach, however very little attention has been paid to the challenges presented by the mixed strategy implementation. In fact, despite the rich empirical literature, it is still not clear how firms that adopt a hybrid strategy may successfully integrate the inherent contradiction of the "Low Cost" and "Differentiation" approaches, escaping from the "Stuck in The Middle" outcome. Consequently, after a careful consultation of the relevant literature, we conclude that several types of hybrid strategy implementation, which should correspond to different business environmental situations, exist. In order to study the characteristics of these different types of hybrid strategies implementations, we propose a typology comprising four types of hybrid strategy implementation, defined by two antecedents of the firm and two antecedents of the environment. As a contribution of this article, the proposed typology has the purpose to fill a methodological gap regarding the adoption of Hybrid strategies and we expect that it could be used as a framework for further studies, aiming to suggest managerial implications and further unveil characteristics of the hybrid implementation. Additionally, we align and contrast the hybrid and ambidextrous approaches, which share many similarities. Despite the fact that they have been confounded in empirical studies, we concluded that hybridity and ambidexterity are distinct and complementary concepts: while hybrid strategy defines the value proposition of the firm (a composition of "Low Cost" and "Differentiation"), ambidexterity focus on how to deliver this value with efficiency (Exploitation) and how to renew it effectively (Exploration).
\end{abstract}

Keywords Hybrid Strategy, Exploration, Exploitation, Ambidexterity, Organizational Architecture, Turbulence, Hypercompetition, Uncertainty

\section{Introduction}

In this literature review, we decided to focus on the study of the adoption of hybrid strategy, also known as combination, mixed or dual strategy [2-4]. Since the success of Porter's generic strategy framework, a long debate between two points of view has taken place: the proponents of Porter's model, who defend that the pursuit of both "Low Cost" and "Differentiation" strategies by a firm would result in a poor performance situation called "Stuck-in-the-Middle", and the proponents of the adoption of hybrid strategy, which involves a combination of "Low Cost" and "Differentiation" elements, who defend superior performance over the pure strategy adoption. At the centre of this debate, the concept of trade-offs has been playing a key role as it could be considered the central part of the coherence of a strategy [5]. Trade-offs are determined by choosing one strategic dimension to the detriment of the other. In the trade-offs paradigm, opposed strategic dimensions could not be pursued at the same time without creating some sort of inefficiency in the firm's value chain $[1,6]$. This is because strategic positioning, such as differentiation and cost leadership, involves contradictory activities and resources allocation that are mutually exclusive. In fact, the choice of a differentiation strategy usually requires an emphasis in product innovation, customer customization, service differentiation and premium image to sustain a premium price. In contrast, a low cost strategy usually requires an emphasis on limited product and service scope, standardization, efficiency through economy of scale and learning curve to achieve a lower cost. Consequently, the firm that does not choose one type of strategy, or tries to implement the two simultaneously, will find itself in a poor performance situation, referenced as "Stuck-in-the-middle" [6]. Numerous empirical studies 
defend this point of view [7-9]. In fact, a firm that chooses a particular position in an industry, which should be by "Low Cost" or "Differentiation" approaches, could sustain a competitive advantage based on two types of sources: the attractiveness of the industry associated to the barriers that could offer protection $[10,6]$ and the set of unique resources that were developed internally that could offer protection through heterogeneity and imperfect mobility [11-13]. Consequently, the rules of trade-offs associated with the industry idiosyncrasy, which shape the strategic choices of this firm, remain valid until these industry characteristics remain unchanged [14]. In such a context of predictability and stability it is recommended and sensible that a firm concentrates its focus on one strategic dimension and specializes in a few competencies.

Conversely, in a turbulent environment marked by a high level of competition, instability of demand and fast transformation of the industry, the rule of trade-offs lose its importance, because at best it has a temporary validity [15]. Consequently, a firm in such a context is forced to deploy a more complex and dynamic approach to strategy $[16,17]$. The modern era of globalization, high speed and instability has been at the origin of this need. In fact, many authors defend that business environments have been much more dynamic, unstable and competitive. These turbulent environments are commonly described by increased competitive intensity, disruptive changes in the industry structure, volatility of demand, and unpredictability of customer behaviour; alongside instability of economic, social and political factors. In these uncertain business environments, firms have been compelled to adapt to survive and to maintain their financial performance. In such a context, the adoption of traditional approaches to strategy, such as the positioning school, which assumes a relatively stable world, has been questioned by the emergence of the hybrid strategy adoption, which seems to be more suitable for adaptation. A voluminous body of theoretical and empirical studies defends the pursuit of a combination of the "Low Cost" and "Differentiation" strategy approach [18-23]. Additionally, several studies demonstrate that firms that have adopted a hybrid approach in a dynamic environment have presented a superior or at least equivalent performance compared to pure strategy ways [3].

However, the hybrid literature has concentrated on the performance linkage and on the debate of countering the pure strategy approach, but very little attention has been paid to the challenges that the mixed strategy implementation present. In fact, despite the rich empirical literature, it has not yet been explained how firms that adopt a hybrid strategy may successfully integrate the inherent contradiction of the "Low Cost" and "Differentiation" approaches, escaping from the "Stuck in The Middle" outcome.

\section{The Link of Hybrid Strategy Adoption with the Environment}

Contrasting with the pure strategy adoption that is more related to a stable environment, hybrid strategy has been associated with a turbulent, dynamic and volatile environment. Turbulent environments require flexible combinations of strategies [24]. The competence of combining harmoniously "Low Cost" and "Differentiation" elements brings flexibility and a capacity for adaptation to an unpredictable and complex business context. Miller [25] advises about the risk of adopting an over-simplified strategic repertoire. An excessively narrowed strategic focus could lead to failure by having a too simple offer, to ignore important consumers' needs, to be easily imitated by rivals and to make difficult the adaptation to a business context changes. Consequently, the study of hybrid strategy has been to some degree related to specific dynamic environmental factors.

Hybrid strategy adoption in an emergent and mature market. Emergent economies have been marked by fast-growing markets and rapid changes but also by high uncertainty, institutional voids and hypercompetition, which create serious strategic challenges for firms [26]. In accordance with this, some studies on hybrid strategy concentrate their study in emergent economies. Gopalakrishna and Subramanian [27] explain how the business environment in India was suddenly transformed from a protected-stable to open-hypercompetitive context: hybrid firms in such an environment demonstrated superior performance over the ones that had adopted a pure approach. They explain these results by the fact that firms that have adopted a hybrid approach are more flexible and adaptable to the fast-changing, complex and hypercompetitive new environment. Acquaah and Yasai-Ardekani [28] find similar results in Ghana, a Sub-Saharan African economy that has been transforming its economy from state-controlled to free market capitalism systems: firms have been suddenly thrown into a fast-growing-hypercompetitive context, and the hybrid adoption demonstrated it to be a viable alternative to superior performance and survival. Li and Li [29], explain how the fast-growing Chinese economy has become one of the most dynamic and competitive business environments, and concluded that hybrid strategy is associated with superior performance. And finally, Kim et al., [30] found that hybrid strategy has superior performance over the pure strategy adoption in a sample of Korean online shopping malls. Studies of hybrid strategy have also been done in developed countries, particularly in mature or recessive economies such as those in Western Europe, who also present turbulent environments such as unpredictability and volatility of demand and supply [23]. Spanos et al., [20], defend empirically that hybrid strategy adoption is maybe the only feasible and attractive strategic alternative for Greek firms to survive in a recessive economy associated with a high competitive environment and with very limited capacity for investment. And, Pertusa-Ortega et al., [3], demonstrated that Spanish firms that pursue a hybrid approach are associated with higher levels of performance.

Hybrid strategy adoption and competitive intensity. Studies on hybrid strategy have also considered 
market-environmental factors, mainly in relation to competitive intensity. In fact, competitive intensity is considered one of the most important factors contributing to environmental hostility $[31,32]$. The literature suggests that firms need to engage in a greater level of entrepreneurial activities, such as exploration, strategic renewal and innovation as environmental hostility intensifies [32,33]. In accordance with this, some studies have tested the relationship between competitive intensity and hybrid strategy adoption and its effect on a firm's performance. Acquaah and Yasai-Ardekani [28] employed market competitive intensity as a control variable to prove that under high competitive intensity firms that adopt the hybrid strategy are superior in performance to those firms that adopt the pure or "Stuck-in-the-Middle" strategic approach. Auh and Menguc [34] tested the effect of competitive intensity on a firm's performance using an ambidexterity approach in the Australian market: they demonstrated that as the level of competition increases, Defenders and Prospectors tend to choose a more balanced approach between exploration and exploitation, which matches the hybrid assumption of effectiveness (differentiation-exploration) and efficiency (Low cost-exploitation) approaches.

In conclusion, most empirical studies on hybrid strategy adoption and its relationship with environmental factors have been focused on the study of competitive intensity. Empirical studies in emergent markets and mature-declining economies are broader and less precise as they are contextual and not linked to specific environmental factors. Consequently, the premise of the relationship of hybrid strategy adoption with a turbulent environment is partially explored. One of the environmental factors not tested by empirical studies is the volatility of demand and changes of preferences of consumers. In fact as Proff [23] explained, changes in customer price sensitivity should require a hybrid approach. Hill [21] and Murray [22] demonstrated in their theoretical studies that customer price sensitivity and the importance given to other attributes are directly related to the adoption of a hybrid approach. Evidence from the literature demonstrates that two environmental situations could define very different types of hybrid adoption. One is related to the adoption of hybrid strategy in a fast growing and changing market accompanied by an increase of competitive intensity [27-29]. In this situation the firm that reached a strong position in one of the two strategies may lead by improving the position of the other [21,3]. Hill [21] exemplifies this with a firm positioned originally as differentiation, which attains an important market share and enjoys the benefits of economy of scale, scope and learning curve. This is possible in a fast-growing market where the initial simple "Differentiation" focus is used as a lever for the "Low Cost" approach. Additionally, for this firm to make the efforts, investments, and risks in implementing an additional "Low Cost" approach to its "Differentiation" strategy, pressures from the environment should come from an increase of competitive intensity.
The second situation is related to the adoption of hybrid strategy in a mature-declining market. Also highly competitive, this market could become turbulent because of uncertainty provoked by volatility of demand or supply. This is much more a survival aspect of hybridity than the growing perspective. In this situation, the market does not allow the benefit of efficiency associated with an increase in volume, because gain of market share is limited or not possible. Uncertainty of demand and supply could brutally affect the offer that will demand a change in the strategic approach. Then a hybrid approach could bring the necessary flexibility for adaptation. In his case study of the German automotive industry, Proff [23] identified six turbulent environmental factors that have been influencing the automotive industry and lead to the adoption of a hybrid approach. On the demand side: a stagnating demand for new cars; an increasing practice of providing the full range of equipment as standard rather than as optional, reducing profit; and the increasing demand for niche product, increasing complexity and cost. On the supply side: an increase of differentiation of product lines with more variety of models; an overcapacity and a decentralization of production have brought an increase of complexity.

Unfortunately, despite the fact that many scholars have cited the use of hybrid strategy for a firm's survival and adaptation, we have not found any empirical studies on the subject to date. That will be of particular interest to study the performance of firms that have used a hybrid strategy to adapt to turbulent environments characterized by uncertainty of demand and volatility of supply in mature-declining markets. Furthermore, based on the different stages of industry life cycle described by Wright et al., [35], we propose that further research should study the characteristics of Hybrid implementation in two distinct market scenarios: The growing and highly competitive market scenario, also referred to as Competitive Turbulence [35] and the mature-declining market with association of unpredictability of demand and/or volatility of supply, which we will refer to as Demand-Supply Turbulence.

\section{Identifying Distinct Pathways To Hybrid Strategy}

Additionally to the different environmental conditions that could shape the type of hybrid adoption, the original characteristics of the firm could play an important role when the firm decided to adopt a hybrid approach. In fact, the use of hybrid strategy involves strategic challenges, complex processes and cultural changes and consequently elevated risks to be managed. One of the main challenges is to deal with the contradictory nature of a duo-focus, to avoid the nullity effect of simultaneously emphasizing opposite goals and to transform them into a complementary effect. It is no easy task and it should not be a natural choice. Ultimately, attaining a competitive advantage through a pure strategy 
approach has an easier and less risky implementation.

Thus it is highly probable that prior to the hybrid adoption the firm had already attained a competitive advantage either by a "Low Cost" or "Differentiation" approach. As we demonstrated, an increase of uncertainty and hostility in the environment could have forced the firm to change its original strategic positioning and to adopt a hybrid approach. It is also not impossible, but less probable that a firm "Stuck in the Middle" migrated directly to a successfully hybrid implementation. This is because this firm that has neither developed a distinctive "Low Cost" or "Differentiation" competency, will have an enormous challenge in developing simultaneously and appropriately the two approaches. On the other hand, the firm that already has a well-developed and established competency will have to develop the new competency without destroying the value generated by the original one. Based on evidence in the literature, two main paths for hybridity were identified. The first one is related to the adoption of a hybrid approach by a firm that is positioned as differentiation. A firm that has been successful in adopting a pure differentiation strategy gains market share, and through the logic of the economy of scale, economy of scope and learning curve, also attains the benefits of a cost advantage $[21,25,36]$. The second situation is when a firm, originally positioned as "Low Cost", decides to complement its strategy through "Differentiation", because it's able to invest its profits in marketing, service or product attributes $[3,21]$.

\section{The Adoption of Hybrid Approach by a Firm Originally Positioned as Pure "Differentiation"}

As explained by Porter [1], firms that choose a differentiation approach create competitive advantage by offering a product or service with unique attributes. This unique offer associated with a customer that is more willing to pay a premium price, allows the firm to sustain superior revenue. The uniqueness of the offer creates two barriers for a rival to enter the market. Firstly, it reduces the bargaining power of the customer, because there are no other offers that allow comparison. Consequently, customers tend to be less sensitive to price and more loyal to the firm's offer. Second, as the "Resource Based View" proponents have elucidated it, the uniqueness attributes of the offer are difficult to be imitated by a rival due to its resources and capabilities complexity. Protected by these barriers, the firm that adopts a "Differentiation" strategy easily sustains superior margin, even if it has to manage a superior cost. But change in the environment could reduce or nullify the protection provided by these barriers. Increases of competitive intensity or change in consumer preferences are the main reason for a firm originally positioned as "Differentiation" to adopt a hybrid approach. It is therefore necessary to distinguish two different types of adaptation. One is related to an increase of competitive intensity, characterising a turbulent competitive environment, where the firm reinforces its actual "Differentiation" positioning with a "Low Cost" approach; we named it the Reinforcement Adaptive Perspective. The second is related to a change in the customer taste, characterising a turbulent demand-supply environment, where the firm modify its actual "Differentiation" positioning with a "Low Cost" approach; we named it the Survival Adaptive Perspective.

The Reinforcement Adaptive Perspective. Hill [21] defends that in certain conditions a firm positioned as differentiation could experience a growth of market share and acquire the benefit of the cost advantage. This is more likely to happen under the following circumstances: when consumers' commitment to the products of rival firms is low, when market growth is high, when market structure is fragmented at the demand side, when the production process is new and complex and when economies of scale and scope exists. Using the advantage of its differentiated brand image associated with a consumer not so loyal to other rivals offers, this firm could adjust down its premium price to reach the larger part of the market consumers. Then supported by a growing market, the increased volume could bring economies of scale that reduce the unitary cost and surpass the additional cost caused by differentiation. A fragmented market could allow the firm to attend different types of consumption need, and create a portfolio of differentiation offers for each consumer segment, acquiring the benefit of economies of scope. Also, complex and new productive processes will complement the cost advantage bringing the benefit of the learning curve effect. A typical example of this type of situation is that of Apple Inc. which originated from a niche premium computer producer and turned into one of the largest electronic device producers for mass consumption. But these circumstances are not sufficient for the differentiated firm to achieve the cost advantage. In the same way that this firm has the core competence to differentiate its product and explore new consumption segments, this firm will have to develop new managerial capabilities of exploitation to take advantage of the cost benefits. Economy of scale, scope and the learning curve will demand a certain focus on cost control, optimization of the production process as well as efficiency.

We named this type of situation the Reinforcement Adaptive Perspective because it is more likely that this firm will take the effort and risk to increase the complexity of its strategy adding a "Low Cost" approach in a growing market as a mechanism to protect its original competitive advantage based on differentiation against an increasing competitive intensity coming from imitators. In fact, an increase of competition is characterised by a proliferation of similar offers on the market. Despite the resources and capabilities complexity of the firm's differentiated offer, which makes it difficult to imitate, access by rivals to knowledge, technology, talents and best practice is not impossible. Knowledge, talent, and new technologies can be easily acquired in the globalized and integrated environments of 
today. In this case, rivals would reach a comparable offer, not an exact one, but sufficiently equivalent in terms of attributes to be comparable. With a multiplicity of choice, the less loyal customers could tend to give more importance to a less expensive offer that has similar value attributes than the offer by the differentiation firm. The increase of a rival's offers also strengthens the customer's bargaining power, pressuring down the average price of the industry, which should provoke an erosion of industry average price and challenge the stability of the firm positioned as differentiation. Wright et al., [35] exemplify this type of situation with the case of Federal Express that occurred in 1992. After having been a leader in its segment with a "Differentiation" strategy approach, the company experienced a loss of consumers who migrated to imitators offering a similar service for a lower price. Federal Express reinforced its position by increasing its differentiation through the offer of new types of service such as "Just In Time" transport and online order tracking, while it was simultaneously lowering its cost through technological-efficiency initiatives to maintain a competitive price.

The Survival Adaptive Perspective. In a mature market where growth is low, brand loyalty is well established and productive processes are already optimized, the achievement of "Low Cost" advantage through "Differentiation" is more difficult because gains of efficiency based on economy of scale, scope and learning curve has already been used [21]. Mature markets are also characterised by competitive intensity because normally the overall offer is greater than the demand that is stabilizing or declining. In this delicate market equilibrium, turbulences coming from the demand or supply side could present a huge challenge of adaptation for a firm positioned as differentiation. An uncertainty on the demand side is when the consumer becomes more sensitive to price due to a disruptive change in the economic environment. An increase of inflation, the interest rate and unemployment rate, could affect consumers' purchasing behaviour that pass on to give more importance to price than other attributes. In such a situation, the firm that has based its premium price on brand image, tailor made service offer, unique design or special added product's features, could be surprised by a loss of its less loyal consumers that suddenly altered their purchase behaviour. In fact, a more pessimist consumer tends to be less willing to spend their income with more sophisticated offers, concentrating their expenses on basic consumption needs. Less differentiated rival's offers could match the needs of these customers that are looking for similar or less value for a more affordable price. That was the case during the crisis of 2008, when Wal-mart captured important market share from other retail chains such as Target and J. C. Penney by having a more affordable offer [37]. More recently, El Corte Inglés, a premium food retail and department store in Spain, in an attempt to adapt to a recessive market, reduced its prices by $25 \%$ while it was focusing on efficiency, inventory working capital and cost reductions [38]. This adaptation was triggered by an important change in the consumer behaviour, which with the economic crisis turned to be more sensitive to price and favoured "Low Cost" rival.

The firm positioned as "Differentiation" will suffer a loss of market share due to the less loyal and more price sensitive customers that migrate to competitor offers. Then the firm has two choices: to stay with the remaining part of the market share or to change the approach of its "Differentiation" strategy. If the firm's option is to remain with a less important part of the market share, the "Differentiation" approach should be strengthened, reinforcing the uniqueness attributes against the rival's offers, which will characterize a migration from a generic to a focus strategic approach. Unfortunately this option is not always available: the migration to a smaller part of the market could not be compensated by an increase of the premium price compared to the increase of unitary cost provoked by the diseconomy of scale. As Hill [21] noted, there exist thresholds of volume production in most industries, where producing under certain volume conditions will not be possible due to high unitary cost. Otherwise, if the firm wants to maintain an important market share, it is logical that this firm will alter its "Differentiation" approach. A new complementary focus on "Low Cost" should be used to make the firm more competitive in the eyes of more price sensitive customers. Different to the Reinforcement Adaptive Perspective, in this situation the firm is intending to review its value proposition, eliminating the attributes that are no longer valuable for the customer, and consequently reducing the overall cost. Additionally to the review of the value proposition, initiatives of cost and expenses reduction not related to scale logic should be undertaken to bring about the necessary competitiveness.

\section{The Adoption of Hybrid Approach by a Firm Originally Positioned as Pure "Low Cost"}

As explained by Porter [1] the firm that chose a "Low Cost" position, is cost minimization oriented, exploits a value logic based on economies of scale, and has a strong focus on cost control. Two barriers protect its advantage. First, by attaining the lowest cost in the industry sustained by its capability of exploiting efficiency and the benefit of economy of scale, scope and learning effect. Second, by its customers who are highly sensitive to price and do not give importance to other attributes. Theoretically, firms that adopt this position can always beat the competition based on price as it is sustained by the lowest cost. However, as Hill [21] demonstrated, there exists a threshold level of market share, where above it, gains of economies of scale, scope or learning curve are minimal. Considering that this threshold in most industries is relatively low, there is no unique "Low Cost" leadership position, and many firms could easily attain an equivalent cost advantage. In this situation, the only way 
for a firm originally positioned as "Low Cost" to remain competitive is to complement its strategy through differentiation. We will explore this type of hybridity through the Reinforcement Adaptive Perspective and the Survival Adaptive Perspective.

The Reinforcement Adaptive Perspective. In a fast-growing market, a firm could choose the "Low Cost" strategy to attain an important share of the market and gain the benefit of scale, scope and learning curve before their rivals. Once established with an important share of the market, the firm will benefit from financial resources to invest in differentiation in order to reinforce its leadership position and create protection against competitors [3,21]. This is possible if in this market, consumers are initially more sensitive to price and as far as the demand side develops; they also give importance to other attributes. Additionally, the fast-growing market should also have a minimum degree of fragmentation and the product and service sold by the firm should present a minimum scope for differentiation. Otherwise, in a non-fragmented market, dominated by highly commoditized products or characterized by customers that give importance only to price, the addition of a differentiation strategy could increase the marginal cost without an equivalent increase of marginal revenue. Wal-mart is an interesting case of a retail store that started with a pure "Low Cost" strategy, with a strong focus on cost control and efficiency, gained an important market share through developing an efficiency competence in supply chain and strengthened its leadership position through differentiation initiatives such as offering a broad assortment and adding new services $[39,40]$.

The Survival Adaptive Perspective. The position of a "Low Cost" firm could be threatened if consumers start to give importance to attributes other than price and if competitors offer products with added values for an equivalent price. If this firm is in a mature market with few opportunities of growth to achieve new levels of economy of scale, then this firm could suffer a loss of market share by the migration of parts of its customer to the rival's offers. Competitors could sustain a competitive price, because having captured new consumers through their attractive offers; they achieve benefit of scale and scope. The central problem for this firm is that its offer remained too simple for the consumers' taste. Consumer behaviour could have changed for two principal reasons. A change in economic environment, such as an increase of middle class income could move the consumption to more sophisticated needs. Then the consumers will give importance to competitors that have a more differentiated offer. The other reason for a change in consumer taste is related to the success of marketing and communication strategy of rivals, who could change the value perception of consumers by provoking and unveiling new needs. Gehani [41] describes how after the 2008 economic slowdown, how a large composite fabric and accessories enterprise transformed its original "Low Cost" positioning to a "Differentiation" positioning in order to escape from an increase of competition coming from emergent countries.

The firm positioned as "Low Cost" could decide to add new value-added features to its offer in an effort to retain market share. In this case, the primary strategy should be complemented by a "Differentiation" approach, retaining old consumers or capturing new ones through the new approach. Adding extra value features to an existing offer will bring a significant challenge as to the development of explorative capabilities and ability of the firm to differentiate its products. Obviously this is possible, if a certain degree of fragmentation in the market exists, and if the offer has sufficient scope for differentiation [21,22]. One of the challenges of this firm in implementing the differentiation complementary approach will be to choose a dimension of differentiation that creates uniqueness in relation to rivals. As this firm could not further extract any benefit from efficiency and economy of scale, there only remains the opportunity for creating competitive advantage on the ability of the firm to differentiate its offer from competitors.

\section{Hybridity and Focus Strategy}

In addition to the competitive advantage dimension (differentiation or low-cost), the Porter model presents also another strategic dimension called focus strategy. A focus strategy is defined by the competitive scope [56] that is more restrict then the broad market scope of a generic Differentiation or Low-cost strategic approach. A focus strategy aims serving a smaller group of customers in a better way than a broader strategic approach that tends serving a large number of customers with the same value proposition. The strength of the focus strategy resigns in designing a more tailored solution and higher intimacy with a group of customers that have specific needs. The focus strategy could be either of a differentiation or Low-cost competitive advantage. A focus strategy based on differentiation will explores uniqueness through tailored product and service solutions for very specific needs while a focus strategy based on low-cost will explores reducing attributes of a generic value proposition that are not valued by a specific small group of customer and has an important impact on the firm value chain to create a cost advantage. A focus strategy is mainly a segmentation strategy and consequently it should be very narrow and suffer less from volatility of customer demand, high level of competition and market turbulence. However, theoretically, the same rules that apply for a broad scope are also valuable for a narrow scope. Consequently if the firm that have adopted a focus strategy suffer from an increase of competition or a disruptive change of customer demand behaviour on its segment, the firm will have to reinforce its original focus strategy or modify it for survival with differentiation or low-cost elements. While, these cases should be rare but not impossible the firm that have adopted a focus strategy will concentrates in altering its single and narrowed value proposition by chirurgical modification of value attributes. By incrementing or reducing attributes of its 
value proposition the firm that chose originally a pure focus strategy could adopt a focus hybrid approach by adjusting its value proposition at an attribute level.

Furthermore, another aspect of the focus approach could have a great relevance for the hybrid strategic implementation. A way to implement a hybrid approach is to adopt a multi-focus strategic approach. A firm that adopts a multi-focus strategy aims to serve several different customer segments. If a firm serve opposed customer needs such as premium and popular segments at the same time, its strategy would be considered a hybrid implementation. Despite that Porter does not cite this situation as a hybrid approach; he sustains deeply the possibility for a firm to explore the advantage of sharing parts of a same firm value chain in order to attend several different customer segments, which he calls it "segment interrelationships" and could be done in a "broadly-targeted strategies" focus scope [56]. A firm that implement hybridity in order to manage two value propositions, one focused on differentiation and another focused on a low-cost approach sharing an important part of the same firm's value chain will have to solve the many trade-offs that should appears to create additional value in comparison to a pure strategic approach. However, the multi-focus strategy seems to be an interesting avenue for hybrid implementation, it will pass through the challenge of solving trade-off dilemmas. As the empirical research on hybridity do not specify how firms have solved these trade-offs or if it has adopted a multi-focus strategy, we suggest that these issues are of higher relevance for further studies.

\section{Hybrid Strategy and Ambidexterity}

Hybrid strategy has been identified as a strategic approach that emphasises both low cost and differentiation strategy $[3,4]$. The pursuit of such a mixed strategy involves the management of contradictory and mutually exclusive choice. Similarly, strategic ambidexterity has been defined as concurrently pursuing, managing and executing an exploitative and explorative focus, which are considered paradoxical strategies [42]. Exploration is determined by activities involving search, experimentation, flexibility, discovery and innovation, while exploitation is defined by activities involving refinement, execution, selection, implementation and efficiency [43]. Both hybrid and ambidexterity have as their main purpose to manage tensional objectives and trade-offs [44] and to lead with performance dilemmas [45]. Ultimately, strategic ambidexterity has been associated with the development of a particular dynamic capability, which has been defined as the organizational competence to transform tension within paradoxical strategies into short-term complementary effects for long-term sustainability [44]. Considering the perspective of managing dual opposite and antagonist strategic focus, we can consider that hybrid strategy and strategic ambidexterity are two approaches with a common purpose. This purpose is associated with the development of an adaptive capability associated with a complex environment.

Despite this, the two perspectives have different origins. On the one hand, hybrid strategy is rooted in the positioning school, specifically in Porter's generic model and to some extent in Miles and Snow's framework[46]. On the other hand, strategic ambidexterity is rooted in the organizational learning school [43,47], organizational ambidexterity $[48,49]$, and the idea of capabilities that found its root in the Resource Based View [42,44]. More recently, strategic ambidexterity has been associated with dynamic capabilities as an extension of the RBV approach $[42,49,50]$. As has already been elucidated, positioning and resource schools constitute the two sides of the same coin and could be considered as complementary [20,51]. A firm should define its strategy to fit the environment and to develop internal competencies that enable it to achieve success. Through this point of view, hybrid and ambidextrous approaches could be envisaged complementary as well. In fact, a firm positioned as "Low Cost", emphasizes its activities on efficiency, economy of scale, cost optimization and reduction. As this firm tends to attain the lowest cost possible, it normally offers a reduced and simplified scope of product and service, in order to achieve maximum efficiency [1]. With a less variable scope, the firm could concentrate on exploitative learning activities such as refinement, operation optimization and gain of efficiency through learning curve to sustain its "Low Cost" positioning.

Conversely, a firm positioned as "Differentiation", emphasizes its activities on the creation of unique offers that allow sustaining premium price. Such an approach concerns the discovery and development of new and unique products and services. Then, it is expected that a firm positioned as differentiation has a well-developed explorative learning activities characterized by the search for new opportunities, scope variation, play, risk taking and experimentation to sustain its competitive advantage based on differentiation. Consequently, a firm that adopted a hybrid strategy which involves the combination of "Low Cost" and "Differentiation" elements in its positioning should have developed an ambidextrous approach in its capabilities development and learning activities.

However, it is important to note that this complementarity came about mainly from different angles. In fact the two theories are concerned with strategic adaptation of environmental change, but while the hybrid approach is concerned with the external aspects of firm's strategy, the ambidexterity theory is more concerned with the internal ones. Having its root in the positioning school, the hybrid approach has the heritage of the external firm perspective choosing a value configuration that is represented by a particular market competitive position. More complex and dynamic in nature than the pure approach, the Hybrid approach combines "Low Cost" and "Differentiation" 
elements, that allows adaptation to the environment change by capacity of altering its value proposition and positioning or managing multiple value propositions and market positions. The ambidexterity perspective rooted in the Organizational Learning School and dynamic capabilities has the same characteristics of complexity and dynamism as it combines exploitative and explorative activities, but is more concerned with the optimization or change of routines, characterising an internal focus of the firm.

Consequently the two approaches work on different dimensions of the adaptive perspective. The hybrid approach represents a capacity of managing a dynamic positioning and value proposition in the market, by the dynamic combination of "Low Cost" and "Differentiation"; while ambidexterity represents the capacity of optimizing this value proposition by "Exploitation" or create new ones by "Exploration". In fact, an activity could create value through a "Low Cost" or a "Differentiation" focus. But independently of its type of value contribution as a routine it could be optimized through "Exploitation" to increase efficiency or could be changed through "Exploration" to enable innovation and flexibility. Then "Exploitation" is not exclusively for a "Low Cost" focus activity, nor is "Exploration" exclusively for a "Differentiation" focus activity. "Exploitation" could increase efficiency both for a "Low Cost" and "Differentiation" activity. Analogously, "Exploration" will increase effectiveness (flexibility) either for a "Low Cost" or a "Differentiation" activity. The conclusion is that "Low Cost - Differentiation" and "Exploitation - Exploration" are two different and independent dimensions that complement each other and should not be confused.

However, this distinction between hybrid and ambidextrous perspective is not explicit and clear in empirical studies. Hybrid strategy has been investigated by testing activities that characterize "Low Cost" and "Differentiation" emphasis. Strategic ambidexterity has been studied by testing activities that characterize explorative and exploitative activities. In Table 1, we classified the dependent variables that have been tested from the main studies of both approaches. As we can see, despite the different nature of the two perspectives, most of them test the same set of variables. In the "Low Cost" and "Exploitation" approaches, variables such as: cost and expenses optimization and reduction; manufacturing and distribution processes improvement; product and service efficiency, quality optimization and standardization; gain of economies of scale and optimal capacity utilization, are commonly tested. In the "Differentiation" and "Exploration" approaches, variables such as: introduction of new products and services; entry into new markets; exploration of new opportunities; gain of market share; innovation of marketing techniques; intensive advertising and promotional actions and brand identification building, are also commonly tested. Thus, despite the fact that the hybrid and ambidexterity approaches are different perspectives, their empirical studies use the same set of variables, resulting in ambiguous results. Nevertheless, it is important to note that some studies on hybrid strategy have tested competitive positioning variables, which is not tested by the strategic ambidexterity approach. Variables such as: "Low Cost - Low Price", rather than competitors; products, services, brands differentiation and sustainability of higher price are considered only by some hybrid studies, demonstrating that the two different approaches have been separated, despite this not being explicitly cited.

In conclusion, empirical studies have failed to distinguish the external strategic approach from the internals ones. Indeed, the fact that a firm places a high emphasis on "Low Cost" and "Differentiation", does not necessarily imply that it has a high emphasis on "Exploitation" and "Exploration". For example, we could have the situation of a firm that has attained a high emphasis on "Low Cost" and "Differentiation" simultaneously but have internally only a high emphasis on "Exploitation". This firm has probably attained a leadership position and it is offering one of the best combinations of unique value with low cost. Once having attained an important market share this firm experienced the benefit of economy of scale and learning curve that brought the benefit of the "Low Cost" advantage. Explorative activities should be intense and important at the beginning for this firm, but now its exploitative activities maintain the performance of the firm. If not threatened by disruptive change, this firm does not need to maintain a high emphasis in explorative activities such as exploration of new opportunities or innovation of new product or services.

Considering this, the confusion made by empirical works in testing the same variables for hybrid and ambidexterity approaches generate ambiguous results and do not elucidate the very important distinction and complementarity that exist between the dynamic adaptation of the firm value proposition and positioning (hybrid approach) from the optimization and renewing of this value proposition (ambidexterity approach). Finally, despite the hybrid and ambidexterity approaches having a common goal of adaptability, that they are complementary by nature and have similar empirical research methods, they should be considered as two different approaches of strategy and treated independently. A very interesting avenue for future researches could be the study of how the two pairs of dimensions "Low cost- Differentiation" and "Exploration-exploitation" are combined. 
Table 1. Comparison of Competitive Strategy Variables Test Between Hybrid Strategy and Ambidexterity Approach

\begin{tabular}{|c|c|c|c|}
\hline Strategic Dimension & Types of variables tested & Hybrid strategy approach & Strategic ambidexterity approach \\
\hline $\begin{array}{l}\text { Operational efficiency, } \\
\text { exploitative activities }\end{array}$ & $\begin{array}{l}\text { Cost optimization, Cost reduction, } \\
\text { Optimize and Reduce material } \\
\text { consumption and expenses. } \\
\text { Improve Manufacturing and } \\
\text { distribution processes. Products, } \\
\text { services efficiency and quality } \\
\text { optimization and standardization. } \\
\text { Gain of economies of scale, } \\
\text { Optimal capacity utilization }\end{array}$ & $\begin{array}{c}{[3,9,27-30,35,53]} \\
{[29,53,54]}\end{array}$ & $\begin{array}{c}{[52]} \\
{[34,42,52,55]} \\
{[34,55]}\end{array}$ \\
\hline Cost advantage & $\begin{array}{l}\text { Lower Cost, Lower price than } \\
\text { competitors }\end{array}$ & {$[3,27-30,35]$} & \\
\hline $\begin{array}{c}\text { Product and service effectiveness, } \\
\text { explorative activities }\end{array}$ & $\begin{array}{l}\text { Innovation, introduction of new } \\
\text { products and services; Extend } \\
\text { product and service range. } \\
\text { Enter new markets; explore new } \\
\text { opportunities; Gain of Market } \\
\text { share. } \\
\text { Innovation in Marketing } \\
\text { techniques; Intensive advertising } \\
\text { and promotion actions. Brand } \\
\text { identification building. }\end{array}$ & {$[9,27,28,30,53,54]$} & {$[34,52,55]$} \\
\hline Differentiation advantage & $\begin{array}{l}\text { Product, service, brand and } \\
\text { marketing differentiation. } \\
\text { Sustainability of higher price. }\end{array}$ & {$[27-29,53,54]$} & \\
\hline
\end{tabular}

\section{A Suggested Typology for Further Studies of Hybrid Strategy}

Despite the fact that the literature strongly defends the importance of the hybrid adoption with a firm's performance, very little attention has been given to the study of the characteristics of the hybrid perspective. Through a literature review, we demonstrated that there exist convincing evidences of very distinct hybrid applications and implementations. Such differences are sustained by two approaches: the type of environment where the hybrid is adopted and the original strategy and cultural characteristics of the firm. Environmental antecedents divide into two polar situations: one characterized by competitive intensity, normally associated with a growing market, this situation is normally associated as hypercompetition or competitive turbulence. The other is characterized by volatility and uncertainty of the demand and supply side, normally associated with a mature or declining market: we named this situation demand-supply turbulence. The adoption of a hybrid strategy for these very different contexts requires different approaches to implementation. In a competitive turbulent environment, where the market is growing and competition intensifies the firm should adopt a reinforcement strategy approach, where the "Low Cost" or "Differentiation" complementation is integrated to reinforce the original positioning: we named this situation the Reinforcement Adaptive Perspective. In a demand-supply turbulent environment, where the market is stagnated and the demand or/and supply side present high volatility the firm should adopt a change strategy approach, where the "Low Cost" or "Differentiation" complementation is integrated to change the original positioning: we named this situation the Survival Adaptive Perspective.

We also identified two different firm's origins for the adoption of a hybrid strategy. One is related to a firm that is originally positioned as "Differentiation" that decides to adopt a hybrid strategy, adding a "Low Cost" approach. We named this type: "Differentiation Originated Hybridity". The other is related with a firm that is originally positioned as "Low Cost" that decides to adopt a hybrid strategy adding a "Differentiation" approach: we named this type: "Cost Originated Hybridity". Based on these two dimensions, environment antecedents and firm antecedents, we suggest the following typology to support further studies of different types of hybrid implementation (Fig. 1). This typology proposition should be both valid and considered to a firm that originally adopted a pure strategic approach on a broad or narrow scope. 


\begin{tabular}{|c|c|c|c|}
\hline \multirow{4}{*}{ 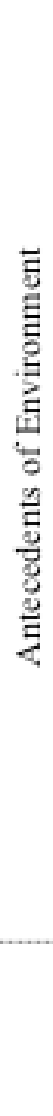 } & 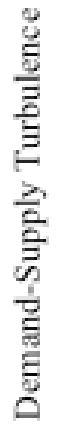 & $\begin{array}{l}\text { A Low Cost Strategy's firm changes its } \\
\text { original positioning adopting a Differentiation } \\
\text { approach as a adaptive mechanism in } \\
\text { response to an increase of uncertainty }\end{array}$ & $\begin{array}{l}\text { A Differentiation Strategy's firm changes its } \\
\text { original positioning adopting a Low Cost } \\
\text { approach as an adaptive mechanism in } \\
\text { response to an increase of uncertainty }\end{array}$ \\
\hline & 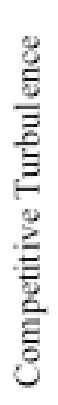 & $\begin{array}{l}\text { A Low Cost Strategy's firm reinforces its } \\
\text { original positioning adopting a differentiation } \\
\text { approach as a protective mechanism against } \\
\text { increase of competition }\end{array}$ & $\begin{array}{l}\text { A Differentiation Strategy's firm reinforces its } \\
\text { original positioning adopting a Low Cost } \\
\text { approach as a protective mechanism against } \\
\text { increase of competition }\end{array}$ \\
\hline & & Cost Originated Hybridity & Differentiation Originated Hybridity \\
\hline & & Antecede & of Firm \\
\hline
\end{tabular}

Figure 1. A Proposed Typology For The Study Of Hybrid Strategy

\section{Conclusions}

The aim of this article is to carry out a systematic review of the literature on the subject of hybrid strategy and to understand its relationship with the concepts of ambidexterity and environments. First, it was identified that the hybrid strategy and ambidexterity approaches share a similar purpose of adaptation but are distinct in nature: the hybrid approach is more concerned with an external view of the firm as inherited by the positioning school, while the ambidexterity approach, which is rooted in a "Resource Based View" perspective is concerned with an internal view of the firm. Secondly, a hybrid strategy involves the composition of "Low Cost-Differentiation" whereas ambidexterity involves the dual focus on "Exploitation-Exploration", two distinct and complementary dimensions: while hybridity defines the strategic value (a composition of "Low Cost" and "Differentiation") of the firm, ambidexterity optimizes (Exploitation) or renews (Exploration) this value. Despite this, most of the empirical studies on hybrid strategy and ambidexterity do not make this distinction and have the same variables in their tests on a firm's performance, leading to ambiguous results. We therefore suggest that future research should make the distinction between the use of hybrid strategic positioning and its ambidexterity implementation.
We also identified different situations that could characterize different types of hybrid implementation. From the environmental linkage, we identified two different types of environment that could characterize diverse approaches of hybrid strategy implementation. One is related to the use of hybrid strategy as a mechanism to reinforce the competitive advantage of the firm in a turbulent competitive environment; we named this situation the Reinforcement Adaptive Perspective. The second is related to the use of hybrid strategy as a mechanism to change the strategic approach of the firm in a demand-supply turbulent environment; we named this situation the Survival Adaptive Perspective. Additionally, we identified two different firm's origins that could characterize different types of hybrid implementation. One is related to a firm originally positioned as "Differentiation" that adopts a "Low Cost" approach, and the other is related to a firm originally positioned as "Low Cost" that adopt a "Differentiation" approach. Based on these distinct situations identified, we proposed a hybrid strategy typology in order to fill an important methodological gap that is present both in theoretical and empirical studies. In fact, situations of hybrid strategy adoptions are incomplete and superficial in the theoretical literatures while it is fragmented and disconnected in the empirical studies. Without a clear identification of environmental and firm antecedents, further studies could not identify effectively 
managerial mechanisms, strategy policies and mainly solutions to trade-off dilemmas that are fundamental to the hybrid strategy implementation success. Each antecedent dimensions present very different type of challenges. The Reinforcement Adaptive Perspective characterized by a competitive turbulence presents the challenge in integrating a complementary opposed strategy to a main successful strategy without losing its original competitive advantage. The Survival Adaptive Perspective presents the challenge in modifying significantly an original strategy to its opposed strategic approach, which requires the substitution of a centric competency by its opposed competency. Among these challenges remains the centric subject of the trade-off dilemmas and solutions that are not cited in the literature. It is expected that the proposed typology in this article will guide and support further studies and allows a refinement and better understanding of the benefit of the hybrid implementation, particularly to elucidate how a firm that has implemented the hybrid approach has combined and solved the paradox of its nature. Additionally, we suggest that the hybrid implementation should be done by a multi-focus strategic approach, where a dual value propositions, one focused on differentiation, the other on low-cost, share the main activities of a common firm's value chain, a situation not cited in literature.

Finally, we conclude that further research on the study of hybrid strategy should have stronger conceptual precision, considering the type of environment and the firm's origins whilst investigating performance and organizational structure. We also suggest that the variables of the hybrid "low cost-differentiation" and ambidexterity "exploitation-exploration" approaches should be studied in a distinct and complementary way.

\section{REFERENCES}

[1] Porter, M. E. (1980). Generic Competitive Strategies.

[2] Markides, C. \& Charitou C. D. (2004). Competing with dual business models: A contingency approach. Academy of Management executive, 18, 3, 24-36.

[3] Pertusa-Ortega, E. M., Molina-Azorín-N, J. F. \& Claver-Cortés S, E. (2009). Competitive Strategies and Firm Performance: a Comparative Analysis of Pure, Hybrid and Stuck-in-the-middle Strategies in Spanish Firms. British Journal of Management, 20, 508-523.

[4] Claver-Cortés, E., Pertusa-Ortega, E. M. \& Molina-Azorín, J. F. (2012). Characteristics of organizational structure relating to hybrid competitive strategy: Implications for performance. Journal of Business Research, 65, 993-1002.

[5] Magretta, J. (2011). Understanding Michael Porter: The Essential Guide to Competition and Strategy. Harvard Business School Press Books, 1.

[6] Porter, M. E. (1996). What Is Strategy? Harvard Business Review, 74, 61-78.
[7] Aulakh, P. S., Kotabe, M. \& Teegen, H. (2000). Export strategies and performance of firms from emerging economies: evidence from Brazil, Chile, and Mexico. Academy of Management Journal, 43, 342-361.

[8] Dess, G. G. \& Davis, P. S. (1982). An Empirical Examination of Porter's (1980) Generic Strategies. Academy of Management, 8, 7-11.

[9] Thornhill, S. \& White, R. E. (2007). Strategic purity: A multi-industry evaluation of pure vs. hybrid business strategies. Strategic Management Journal, 28, 553-561.

[10] Porter, M. E. (1981). The Contributions of Industrial Organization To Strategic Management. Academy of Management Review, 6, 609-620.

[11] Barney, J. (1991). Firm Resources and Sustained Competitive Advantage. Journal of Management, 17, 99-120.

[12] Peteraf, M. A. (1993). The cornerstones of competitive advantage: a resource-based view. Strategic Management Journal, 14, 179-191.

[13] Amit, R. \& Schoemaker, P. J. H. (1993). Strategic Assets and Organizational Rent. Strategic Management Journal, 14, $33-46$.

[14] Spanos, Y. E. \& Lioukas, S. (2001). An examination into the causal logic of rent generation: contrasting porter's competitive strategy framework and the resource-based perspective. Strategic Management Journal, 22, 907.

[15] D'aveni, R. A., Dagnino, G. B. \& Smith, K. G. (2010). The age of temporary advantage. Strategic Management Journal, 31, $1371-1385$.

[16] Chakravarthy, B. (1997). A New Strategy Framework for Coping with Turbulence. Sloan Management Review, 38, 2, 69-82.

[17] Lapersonne, A. H. H. (2013). Managing multiple sources of competitive advantage in a complex competitive environment. Future Studies Research Journal. 5, 2, 221-251.

[18] Beal, R. M. \& Yasai-Ardekani, M. (2000). Performance Implications of Aligning CEO Functional Experiences with Competitive Strategies. Journal of Management, 26, 733-762.

[19] Phillips, L. W., Chang, D. R. \& Buzzell, R. D. (1983). Product Quality, Cost Position and Business Performance: A Test of Some Key Hypotheses. Journal of Marketing, 47, 26.

[20] Spanos, Y. E., Zaralis, G. \& Lioukas, S. (2004). Strategy and industry effects on profitability: evidence from Greece. Strategic Management Journal, 25, 139-165.

[21] Hill, C. W. L. (1988). Differentiation Versus Low Cost or Differentiation and Low Cost: A Contingency Framework. Academy of Management Review, 13, 401-412.

[22] Murray, A. I. (1988). A Contingency View of Porter's "Generic Strategies". Academy of Management Review, 13, 390-400.

[23] Proff, H. (2000). Hybrid strategies as a strategic challenge the case of the German automotive industry. Omega, 28, 541-553.

[24] Kim, E. \& Mcintosh, J. C. (1999). Strategic Organizational Responses to Environmental Chaos. Journal of Managerial 
Issues, XI, 3, 344-362.

[25] Miller, D. (1992). The Generic Strategy Trap. Journal of Business Strategy. 13, 1, 37-41.

[26] Hoskisson, R. E., Eden, L., Lau, C. M. \& Wright, M. (2000). Strategy in Emerging Economies. Academy of Management Journal, 43, 249-267.

[27] Gopalakrishna, P. \& Subramanian, R. (2001). Revisiting the Pure versus Hybrid Dilemma. Journal of Global Marketing, $15,61-79$.

[28] Acquaah, M. \& Yasai-Ardekani, M. (2008). Does the implementation of a combination competitive strategy yield incremental performance benefits? A new perspective from a transition economy in Sub-Saharan Africa. Journal of Business Research, 61, 346-354.

[29] Li, C. B. \& Li, J. J. (2008). Achieving Superior Financial Performance in China: Differentiation, Cost Leadership, or Both? Journal of International Marketing, 16, 1-22.

[30] Kim, E., Nam, D.-I. \& Stimpert, J. L. (2004). The Applicability of Porter's Generic Strategies in the Digital Age: Assumptions, Conjectures, and Suggestions. Journal of Management, 30, 569-589.

[31] Dess, G. G. \& Beard, D. W. (1984). Dimensions of Organizational Task Environments. Administrative Science Quarterly, 29, 52-73.

[32] Zahra, S. A. \& Covin, J. G. (1995). Contextual influences on the corporate entrepreneurship-performance relationship: a longitudinal. Journal of Business Venturing, 10, 43.

[33] Zahra, S. A. (1993). Environment, corporate entrepreneurship, and financial performance: A taxonomic approach. Journal of Business Venturing, 8, 319-340.

[34] Auh, S. \& Menguc, B. (2005). Balancing exploration and exploitation: The moderating role of competitive intensity. Journal of Business Research, 58, 1652-1661.

[35] Wright, P., Kroll, M. J., Parnell, J.A. (1998). Strategic management: concepts. Prentice Hall, Inc.

[36] Miller, D. \& Friesen, P. H. (1986). Porter's (1980) Generic Strategies and Performance: An empirical examination with American data. Part I: Testing Porter. Organization Studies. $7,1,37-55$.

[37] Wal-Mart's Low Prices Mean Big Profits In Crisis Huffington Post, November 13, 2008. http://www.huffingtonpost.com/2008/11/13/walmarts-low-pr ices-mean-_n_143494.html

[38] El Corte Inglés reduce price and margin. Valor econômico, August 26, 2013. http://www.valor.com.br/imprimir/noticia/3246180/em presas/3246180/el-corte-ingles-reduz-precos-e-marge $\mathrm{m}$

[39] Baroto, M. B., Bin Abdullah, M. M., \& Wan, H. L. (2012). Hybrid Strategy: A New Strategy for Competitive Advantage. International Journal of Business and Management, 7, 20, 120-133.

[40] Dess, G. G., Lumpkin, G. T., Eisner, A. \& Mcnamara, G.
(2012). Strategic Management. Creating Competitive Advantages. McGraw-Hill. 6th edition.

[41] Gehani, R. R. (2013). Innovative Strategic Leader Transforming From a Low-Cost Strategy to Product Differentiation Strategy. Journal of Technology Management \& Innovation. 8, 2, 144-155.

[42] Han, M. \& Nikhil, C. (2008). Strategic ambidexterity and performance in international new ventures. Canadian Journal of Administrative Sciences / Revue Canadienne des Sciences de l'Administration, 25, 335-349.

[43] March, J. G. (1991). Exploration and Exploitation in Organizational Learning. Organization Science, 2, 71-87.

[44] Han, M. (2007). Achieving superior internationalization through strategic ambidexterity. Journal of Enterprising Culture, 15, 43-77.

[45] Chakravarthy, B. \& Lorange P. (2008). Driving renewal: the entrepreneur-manager. Journal of Business Strategy, 29, 2, 14-21.

[46] Miles, R. E., Snow, C. C., Meyer, A. D. \& Coleman, J. H. J. (1978). Organizational Strategy, Structure, and Process. Academy of Management Review, 3, 546-562.

[47] Duncan, R. (1976). The ambidextrous organization: Designing dual structures for Innovation. The Management of organization, 1, 167-188. New York. North Holland.

[48] Simsek, Z. (2009). Organizational Ambidexterity: Towards a Multilevel Understanding. Journal of Management Studies, 46, 597-624.

[49] Gibson, C. B. \& Birkinshaw, J. (2004). The antecedents, consequences, and mediating role of organizational ambidexterity. Academy of Management Journal, 47, 209-226.

[50] O'reilly Iii, C. A. \& Tushman, M. L. (2008). Ambidexterity as a dynamic capability: Resolving the innovator's dilemma. Research in Organizational Behavior, 28, 185-206.

[51] Wernerfelt, B. 1984. A resource-based view of the firm. Strategic Management Journal, 5, 171-180.

[52] He, Z.-L. \& Wong, P.-K. (2004). Exploration vs. Exploitation: An Empirical Test of the Ambidexterity Hypothesis. Organization Science, 15, 481-494.

[53] Santos-Vijande, M. L., López-Sánchez, J. Á. \& Trespalacios, J. A. (2012). How organizational learning affects a firm's flexibility, competitive strategy, and performance. Journal of Business Research, 65, 1079-1089.

[54] Wright, P., Kroll, M. J., Tu, H. \& Helms, M. (1991). Generic Strategies and Business Performance: an Empirical Study of the Screw Machine Products Industry. British Journal of Management, 2, 57.

[55] Menguc, B. \& Auh, S. (2008). The asymmetric moderating role of market orientation on the ambidexterity-firm performance relationship for prospectors and defenders. Industrial Marketing Management, 37, 455-470.

[56] Porter, M. E. (1985). Competitive Advantage. Creating and Sustaining Superior Performance. The Free Press. 